\title{
Hyperin protects against cisplatin-induced liver injury in mice ${ }^{1}$
}

\author{
Chengwei Niu', Man Ma", Xiao Han"', Zimin Wang"v, Hangyan Li"
}

'PhD, College of Pharmacy, Jiangsu Food and Pharmaceutical Science College, China. Conception, design, intellectual and scientific content of the study; acquisition, analysis and interpretation of data; technical procedures; statistical analysis; manuscript preparation and writing; critical revision.

"Undergraduate, College of Pharmacy, Jiangsu Food and Pharmaceutical Science College, China. Acquisition of data, technical procedures, manuscript preparation.

"'Undergraduate, Pathology Department, Huai an Hospital of Huai'an, China. Histopathological examinations.

Iv Undergraduate, College of Pharmacy, Jiangsu Food and Pharmaceutical Science College, China. Technical procedures, manuscript preparation.

\begin{abstract}
Purpose: To evaluate the effect of hyperin in cisplatin-induced liver injury in mice.

Methods: Mice were pretreated with hyperin at doses of $25 \mathrm{mg} / \mathrm{kg}$ and $50 \mathrm{mg} / \mathrm{kg}$, respectively, for six days, and intraperitoneal injection of cisplatin $(40 \mathrm{mg} / \mathrm{kg}$ ) was administrated one hour after the final intragastrication of hyperin. Twenty-four hours later, blood and liver were collected for further research.

Results: A single injection of cisplatin $(40 \mathrm{mg} / \mathrm{kg}$ ) for $24 \mathrm{~h}$ significantly increased serum alanine and aspartate aminotransferases (ALT/AST) and gamma glutamyl transferase (GGT) activities, whileas hyperin reversed cisplatin-induced such increases. Liver histopathological examination further demonstrated the protection of hyperin against cisplatin-induced liver injury. Further results showed hyperin reversed cisplatin-induced the increase in content of malondialdehyde (MDA) and the decrease in level of total antioxidant capacity (T-AOC) in liver. Moreover, hyperin increased the levels of superoxide dismutase (SOD), catalase (CAT), glutathione (GSH), glutathione peroxidase (GPx), glutathione-s transferase (GST) in cisplatininduced liver.
\end{abstract}

Conclusion: Hyperin inhibits cisplatin-induced hepatic oxidative stress, which contributes greatly to the amelioration of cisplatin-induced liver injury in mice.

Key words: Cisplatin. Chemical and Drug Induced Liver Injury. Oxidative Stress. Mice. 


\section{Introduction}

Chemotherapy plays an important role in the treatment of cancer nowadays. In spite of the benefits available, it is also accompanied with potent side effects. The severe reactions of chemotherapeutic agents are a major limitation to the use of drug in the clinic ${ }^{1}$.

Cisplatin is a potent chemotherapeutic agent used for the treatment of a wide range of cancer such as ovarian, cervical, and head and neck cancers ${ }^{2,3}$. Cisplatin is becoming increasingly a favor to clinical doctors attributed to its unique clinical benefit. Unfortunately, cisplatin therapy brings about undesirable side effects, including renal dysfunction ${ }^{4}$, ototoxicity ${ }^{5}$, nausea and vomiting $^{6}$, and hepatotoxicity ${ }^{7}$. Hepatotoxicity is not considered to be a dose limiting toxicity for cisplatin, but liver toxicity can occur when it is administered at high doses ${ }^{8}$, which has been an obstacle for the further usage of cisplatin.

Flavonoids are plant polyphenols found in vegetables, fruit and beverages of plant origin, and are well known for owning to their considerable health benefits ${ }^{9,10}$. Hyperin, a flavonoid compound occurring in natural plants, has been demonstrated to exert a variety of biological activities, including antioxidant ${ }^{11,12}$, anti-inflammatory ${ }^{13}$, anticancer ${ }^{14}$, and cardiovascular protective effects ${ }^{15}$. Besides, hyperin is reported to have hepato-protective activity ${ }^{16,17}$. Furthermore, hyperin induces apoptosis in cancer cell and sensitizes it to cisplatin treatment ${ }^{18}$. It has also been demonstrated that hyperin protects against cisplatin-induced acute kidney injury in mice ${ }^{19}$. However, the effect of hyperin in hepatoprotection during cisplatin administration has not been reported so far. In the present study, the effect of hyperin on cisplatin-induced liver injury was investigated.

\section{Methods}

Male ICR mice (body weight 18-22 g) were obtained from Yangzhou University (Yangzhou, China). The mice had access to standard diet and water was given ad libitum. Experiments were conducted in accordance with the institutional animal care guidelines approved by Huai'an Institute for Food and Drug Control. The animals were randomly separated into 4 groups. The mice in group 1 were served as vehicle group, which were given orally $0.9 \%$ normal saline throughout the experiment. The mice in group 2 were served as cisplatin group, which were injected intraperitoneally (i.p.) cisplatin $(40 \mathrm{mg} / \mathrm{kg}$, dissolved in $0.9 \%$ normal saline) only once on the sixth day. The mice in groups 3,4 were served as hyperin $(25,50 \mathrm{mg} /$ $\mathrm{kg}$ ) + cisplatin groups, which were administrated intragastrically (i.g.) hyperin $(25,50 \mathrm{mg} / \mathrm{kg}$ per day) for six consecutive days, and one hour after the final administration of hyperin, cisplatin was injected intraperitoneally. The dose selection was based on the literatures ${ }^{16,20,21}$ and our preliminary experiment. 24 hours later, blood samples were collected by extirpating the eyeball, approximately $0.8 \mathrm{ml}$ per mice, and then mice were sacrificed, finally their livers were removed for further research.

\section{Drugs and reagents}

Hyperin (HPLC purity > 98\%) was purchased from Nanjing Goren Biotech Co., Ltd. (Nanjing, China). Cisplatin was purchased from Sigma Chemical Co. (St. Louis, MO). The kits of AST, ALT, GGT, MDA, T-AOC, SOD, CAT, GSH, GST and GPx were all purchased from Nanjing Jiancheng Bioengineering Institute (Nanjing, China).

\section{Serum biochemistry}

The blood samples obtained were allowed to keep for $2 \mathrm{~h}$ at room temperature, and then centrifugated at $3.500 \mathrm{rpm}$ for 10 $\min$. The supernatant serum was transferred to new tubes for further analysis. Serum alanine/ 
aspartate aminotransferase (ALT/AST), gamma glutamyl transferase (GGT) activities were determined with commercial kits according to the instructions of manufacturer.

\section{Histopathological examination}

The formalin-fixed liver samples were embedded in paraffin, and then sectioned $5 \mu \mathrm{m}$. The sections were stained with haematoxylin and eosin. The slides obtained were mounted and visualized under a light microscope for histological evaluation.

\section{Measurement of lipid peroxidation (LPO) in} liver

Liver tissue was homogenized in ice-cold $0.9 \%$ normal saline. Malondialdehyde (MDA) was assayed by the manufacturer's instruction. MDA reacts with TBA to form the product with the wavelength of maximum absorption at 532 $\mathrm{nm}$. The corresponding protein concentrations were measured according to the Bradford assay. The MDA level in liver was calculated based on protein concentrations of samples and expressed as nmols of MDA/mg protein.

\section{Determination of total antioxidant capacity (T-AOC)}

In the presence of antioxidants in the liver, $\mathrm{Fe}^{3+}$ was reduced to $\mathrm{Fe}^{2+}$. The latter can form a stable complex, which was measured with colorimetric assay. The specific process was carried out according to the instruction of manufacture. The results were assessed based on protein concentration of the corresponding sample.

\section{Measurement of GSH content}

The reduced GSH in liver was detected following the instructions on the commercial kits. The final absorbance was measured at 420 $\mathrm{nm}$ and results were normalized by the protein concentration of corresponding sample as measured by Bradford assay.

\section{Enzymatic assays}

Hepatic tissue was homogenized in precooling normal saline and centrifuged at $3500 \mathrm{r} / \mathrm{min}$ for $15 \mathrm{~min}$. The supernatant obtained was used for the measurement of SOD, CAT, GPx and GST, which were determined according to the manufacturer's instructions respectively. The results were assessed based on protein concentration of the corresponding sample.

\section{Statistical analysis}

All of the values were presented as mean \pm standard error (SE). Statistical analysis was performed using one-way analysis of variance (ANOVA) test with LSD and homogeneity of variance test. $P<0.05$ was considered as statistically significant difference.

\section{Results}

Hyperin prevented cisplatin-induced the increase of serum ALT, AST and GGT activities

ALT, AST and GGT activities in serum are the biomarkers for liver function, and their significant elevation generally reflects acute liver injury ${ }^{22}$. As shown in Figure 1, the serum activities of ALT, AST and GGT obviously increased in cisplatin-treated mice as compared to control $(P<0.001)$. Meanwhile, oral administration of hyperin $(50 \mathrm{mg} / \mathrm{kg}$ ) for 6 days could obviously prevent cisplatin-induced such increase $(P<0.01)$. Hyperin $(25 \mathrm{mg} / \mathrm{kg})$ had no effect on the elevated serum ALT and GGT activities induced by cisplatin, while the increased AST activity obviously decreased with the administration of hyperin $(25 \mathrm{mg} / \mathrm{kg}$ ) $(P<0.05)$ (Figure 1$)$. 


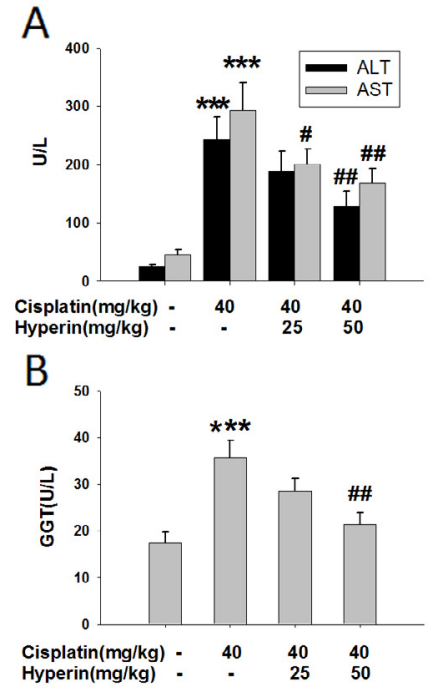

Figure 1 - Hyperin prevented cisplatin-induced the increase of serum ALT, AST and GGT activities. (A) The serum ALT and AST activities. (B) The serum GGT activity. Data were shown as means $\pm S E,(n=9$ 10). ${ }^{* * *} \mathrm{p}<0.001$ vs. control group, $\# \mathrm{p}<0.05, \# \#$ $\mathrm{p}<0.01$, vs. cisplatin-treated group.

\section{Histopathological analysis}

As compared to control liver (Figure 2a), the liver treated with cisplatin exhibited serious liver damage, indicated by obvious hepatocyte steatosis with vacuoles in the cytoplasm (Figure $2 b)$. Interestingly, hyperin $(50 \mathrm{mg} / \mathrm{kg}$ ) strongly prevented cisplatin-induced hepatic lesions (Figure 2c).

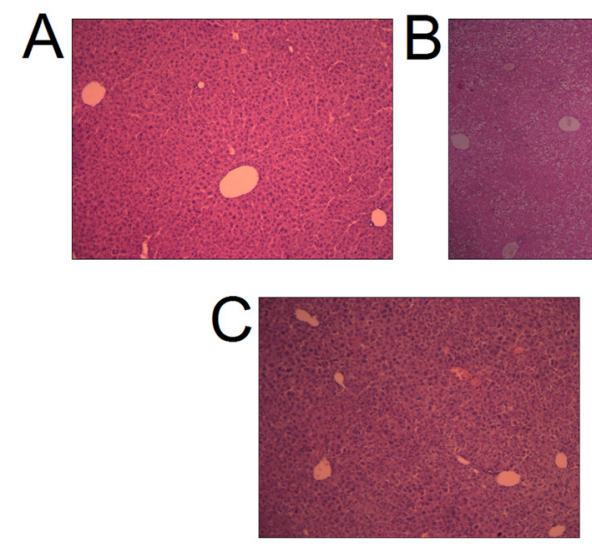

Figure 2 - Hyperin reversed cisplatin-induced liver histopathological changes. Liver sections were stained with hematoxylin-eosin. (a) Control group, (b) Cisplatin only group, (c) Cisplatin+ Hyperin (50 $\mathrm{mg} / \mathrm{kg}$ ) group, $(\mathrm{x} 100)$.
Hyperin reversed cisplatin-induced the changes of MDA and T-AOC levels in liver.

As shown in Figure 3, a single administration of cisplatin significantly increased MDA content and decrease T-AOC level in liver $(P<0.001, P<0.01)$, while hyperin $(50 \mathrm{mg} / \mathrm{kg}$ ) pretreatment reversed such changes $(P<0.05)$. However, pretreatment with hyperin $(25 \mathrm{mg} / \mathrm{kg})$ had no effect on liver MDA and T-AOC levels.

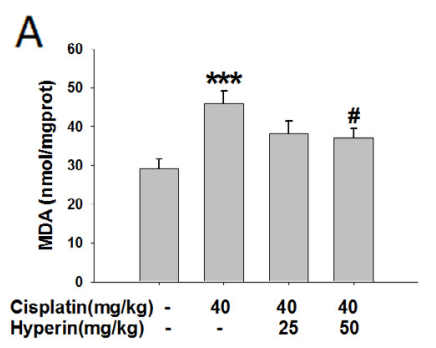

B

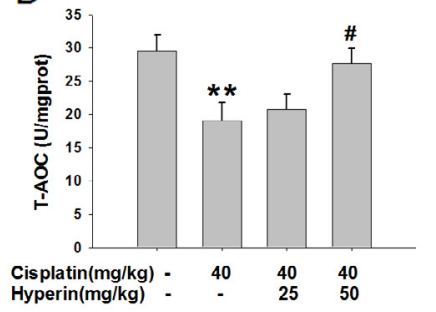

Figure 3 - Hyperin reversed cisplatin-induced the changes of MDA and T-AOC levels in liver. (A) Liver MDA content, (B) Liver T-AOC level. Data were shown as means $\pm S E,(n=9-10)$. ${ }^{* *} p<0.01$, $* * * \mathrm{p}<0.001$ vs. control, $\# \mathrm{p}<0.05$ vs cisplatin-treated group.

\section{Hyperin increased cisplatin-induced the decreased activities of SOD and CAT in liver}

The results in Figure 4 showed that there was an significant decrease in hepatic SOD and CAT activities in cisplatin-induced mice $(P<0.05, P<0.01)$, the hepatic activities of SOD and CAT obviously increased with the administration of hyperin $(50 \mathrm{mg} / \mathrm{kg})(P<0.05)$. 
However, there were no obvious improvements in hepatic activities of SOD and CAT in hyperin (25 mg/kg)-treated mice.
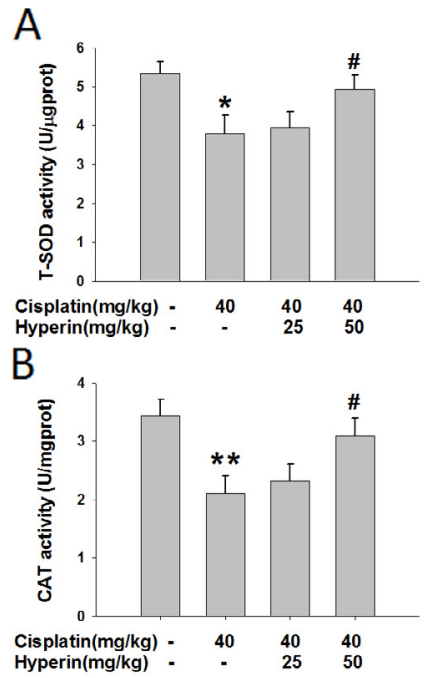

Figure 4 - Hyperin increased cisplatin-induced the decreased activities of SOD and CAT in liver. (A) Liver SOD activity, (B) Liver CAT activity. Data were shown as means $\pm S E,(n=9-10) .{ }^{*} p<0.05,{ }^{* *} p<0.01$ vs. control, $\# \mathrm{p}<0.05$ vs. cisplatin-treated group.

Hyperin increased the levels of GSH, GPx and GST in cisplatin-induced liver

There is a significantincrease of GSHlevel in hyperin $(50 \mathrm{mg} / \mathrm{kg}$ )-treated mice compared with cisplatin $(40 \mathrm{mg} / \mathrm{kg})$ group $(P<0.05)$. Cisplatin decreased hepatic activities of GPx and GST $(P<0.001, P<0.01)$, while hyperin (50 $\mathrm{mg} / \mathrm{kg}$ ) could increase the decreased hepatic activities of GPx and GST induced by cisplatin $(P<0.05)$. However, hyperin $(25 \mathrm{mg} / \mathrm{kg})$ had no effect on cisplatin-induced decreased levels of GPx and GST in liver (Figure 5).
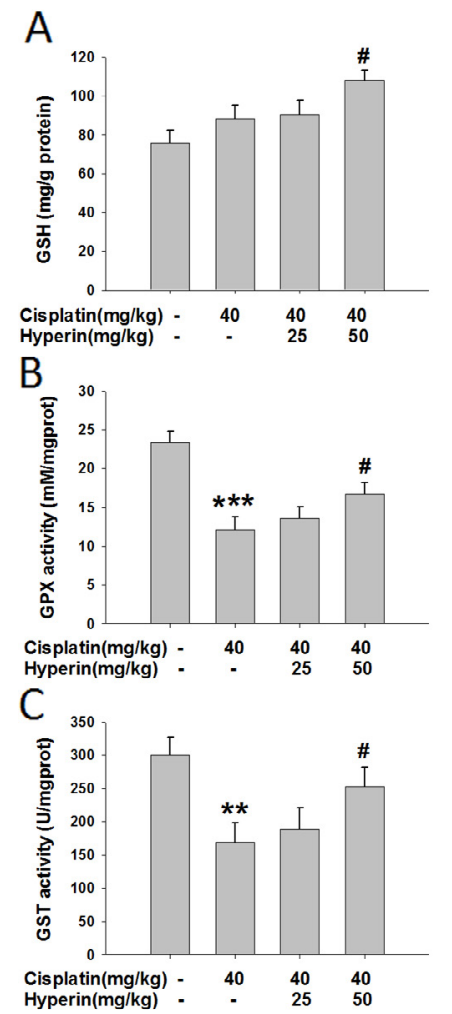

Figure 5 - Hyperin increased the levels of GSH, GPx and GST in cisplatin-induced liver. (A) Liver GSH level, (B) Liver GPx activity, (C) liver GST activity. Data were shown as means $\pm S E,(n=9$ 10). ${ }^{* *} p<0.01, * * * p<0.001$ vs. control, $\# p<0.05$ vs. cisplatin-treated group.

\section{- Discussion}

The significant increase of ALT, AST and GGT activities in serum is commonly used as a marker for liver injury ${ }^{22}$. As shown in Figure 1 , hyperin can prevent cisplatin-induced liver injury, as indicated by the decreased ALT, AST, and GGT activities in serum which are elevated after cisplatin treatment. Histological analysis further confirmed the protection of hyperin against cisplatin-induced liver injury (Figure 2 ). It is reported that hyperin could protect against hepatotoxin-induced liver diseases ${ }^{16,17}$. In addition, hyperin has been demonstrated 
to prevent cisplatin-induced renal damage in mice $^{19}$. The present results demonstrated the protection of hyperin against cisplatin-induced liver injury.

There are increasing evidences that oxidative stress plays a critical role in liver diseases ${ }^{23-25}$. Harmful stimulation induces the excessive generation of reactive oxygen species (ROS) in liver. Level of cellular antioxidant depletion exceeds the level of ROS production and ultimately leads to the development of liver injury. The changes of oxidant and antioxidant system in liver of mice exposure to cisplatin with or without preadministration of hyperin were investigated. As shown in Figure 3 , there was a significant decrease in T-AOC level and increase in MDA content in cisplatintreated liver, indicating that cisplatin could decrease the defense of anti-oxidative system and induce liver oxidative stress injury. While hyperin pretreatment reversed such changes, suggesting that hyperin could improve the defensive ability of anti-oxidant system against hepatic oxidative stress injury.

Cellular antioxidant enzymes play an important role in defense against oxidative stress. SOD and CAT, the main cellular antioxidant enzymes, function mutually to scavenge ROS produced during the oxidative stress $^{26}$. SOD converts the superoxide into hydrogen peroxide ${ }^{27}$, while CAT can then catalyze it into toxic free substances ${ }^{28}$. As shown in Figure 4, hyperin prevented the decrease in liver activities of SOD and CAT induced by cisplatin, suggesting that SOD and CAT may participate in the protection of hyperin against cisplatin-induced liver oxidative stress injury.

$\mathrm{GSH}$, an important part of the antioxidative defense system, is a non-enzymatic antioxidant plays a vital role in protection of cells against exogenous toxic substances ${ }^{29}$. In the research, we detected the GSH content to evaluate the protective effect of hyperin against cisplatin-induced oxidative stress injury. Our results in Figure $5 \mathrm{~A}$ showed that GSH content in liver of mice exposure to cisplatin significantly increased, suggesting cisplatin may cause oxidative stress injury and body induces the excess increase of GSH to resist thus injury. While hyperin could further enhance the GSH content, suggesting hyperin protects hepatocytes against the damage of cisplatin via increasing the GSH content.

GPx and GST are glutathione-related enzymes and they participate in the oxidative stress process with GSH. GPx converts $\mathrm{H}_{2} \mathrm{O}_{2}$ and hydroperoxides to non-toxic products in the presence of GSH and GST catalyzes the conjugation of reactive metabolites with $\mathrm{GSH}^{30,31}$. In the present study, the decreased liver activities of GPx and GST in cisplatininduced mice significantly increased with the pretreatment of hyperin (Figure 5B,C), indicating that hyperin protects against cisplatin-induced liver oxidative stress injury via enhancing the activities of glutathionerelated enzymes.

\section{- Conclusion}

Hyperin protects against the liver injury induced by cisplatin via inhibiting liver oxidative stress injury in mice. Further research is in progress in our laboratory to explore the effect of hyperin on antitumor activity of cisplatin.

\section{References}

1. Turan MI, Siltelioglu Turan I, Mammadov R, Altinkaynak K, Kisaoglu A. The effect of thiamine and thiamine pyrophosphate on oxidative liver damage induced in rats with cisplatin. Biomed Res Int. 2013 Jun; 2013:783809. PMID: 23841092.

2. Karadeniz A, Simsek N, Karakus E, Yildirim S, Kara A, Can I, Kisa F, Emre H, Turkeli M. Royal jelly modulates oxidative stress and apoptosis in liver and kidneys of rats treated with cisplatin. Oxid Med Cell Longev. 2011 Aug; 2011:981793-802. PMID: 21904651. 
3. Dkhil MA, Al-Quraishy S, Aref AM, Othman MS, El-Deib KM, Abdel Moneim AE. The potential role of Azadirachta indica treatment on cisplatin-induced hepatotoxicity and oxidative stress in female rats. Oxid Med Cell Longev. 2013 Dec; 2013:741817. PMID: 24369490.

4. Rathinam R, Ghosh S, Neumann WL, Jamesdaniel $S$. Cisplatin-induced apoptosis in auditory, renal, and neuronal cells is associated with nitration and downregulation of LMO4. Cell Death Discov. 2015 Nov; 1:15052-69. PMID: 26925255.

5. Talach T, Rottenberg J, Gal B, Kostrica R, Jurajda M, Kocak I, Lakomy R, Vogazianos E. Genetic risk factors of cisplatin induced ototoxicity in adult patients. Neoplasma. 2016 Jan; 63(2):263-8. PMID: 26774148.

6. Ranganath $\mathrm{P}$, Einhorn L, Albany C. Management of Chemotherapy Induced Nausea and Vomiting in Patients on Multiday Cisplatin Based Combination Chemotherapy. Biomed Res Int. 2015 Sep; 2015:943618-25. PMID: 26425563.

7. Cho YE, Singh TS, Lee HC, Moon PG, Lee JE, Lee MH, Choi EC,Chen YJ, Kim SH, Baek MC. In-depth identification of pathways related tocisplatin-induced hepatotoxicity through an integrative method based on an informatics-assisted label-free protein quantitation and microarray gene expression approach. Mol Cell Proteomics. 2012 Jan;11(1):M111.010884. PMID: 22023808.

8. Mansour HH, Hafez HF, Fahmy NM. Silymarin modulates Cisplatin-induced oxidative stress and hepatotoxicity in rats. J Biochem Mol Biol. 2006 Nov; 39(6):656-61. PMID: 17129399.

9. Lv X, Zhao S, Ning Z, Zeng H, Shu Y, Tao O, Xiao C, Lu C, Liu Y. Citrus fruits as a treasure trove of active natural metabolites that potentially provide benefits for human health. Chem Cent J. 2015 Dec;9:68-85. PMID: 26705419.

10.Bladé $C$, Aragonès $G$, Arola-Arnal $A$, Muguerza B, Bravo $\mathrm{Fl}$, Salvadó MJ, Arola L, Suárez M. Proanthocyanidins in health and disease. Biofactors. 2016 JanFeb;42(1):5-12. PMID: 26762288.

11.Luo Z, Wang S, Wang D. Phenolic profiles and antioxidant capacities of crude extracts and subsequent fractions from Potentilla fruticosa L. leaves. Nat Prod Res. 2016 Aug;30(16):1890-5. PMID: 26371751.
12. Holzer VM, Lower-Nedza AD, Nandintsetseg $\mathrm{M}$, Batkhuu J, Brantner AH. Antioxidant Constituents of Cotoneaster melanocarpus Lodd. Antioxidants (Basel). 2013 Oct;2(4):265-72. PMID: 26784464.

13.Ku SK, Zhou W, Lee W, Han MS, Na M, Bae JS. Anti-inflammatory effects of hyperoside in human endothelial cells and in mice. Inflammation. 2015 Apr;38(2):784-99. PMID: 25097077.

14.Boukes GJ, van de Venter M. The apoptotic and autophagic properties of two natural occurring prodrugs, hyperoside and hypoxoside, against pancreatic cancer cell lines. Biomed Pharmacother. 2016 Oct;83:617-26. PMID: 27459118.

15. Hou JY, Liu Y, Liu L, Li XM. Protective effect of hyperoside on cardiac ischemia reperfusion injury through inhibition of ER stress and activation of Nrf2 signaling. Asian Pac J Trop Med. 2016 Jan;9(1):76-80. PMID: 26851792.

16.Xie W, Jiang Z, Wang J, Zhang X, Melzig MF. Protective effect of hyperoside against acetaminophen (APAP) induced liver injury through enhancement of APAP clearance. Chem Biol Interact. 2016 Feb;25:246:11-9. PMID: 26772156.

17.Zou L, Chen S, Li L, Wu T. The protective effect of hyperoside on carbon tetrachlorideinduced chronic liver fibrosis in mice via upregulation of Nrf2. Exp Toxicol Pathol. 2017 Apr; pii: S0940-2993(16)30134-8. PMID: 28434817.

18.Zhu X, Ji M, Han Y, Guo Y, Zhu W, Gao F, Yang $X$, Zhang C. PGRMC1-dependent autophagy by hyperoside induces apoptosis and sensitizes ovarian cancer cells to cisplatin treatment. Int J Oncol. 2017 Mar;50(3):83546. PMID: 28197632.

19. Chao CS, Tsai CS, Chang YP, Chen JM, Chin HK, Yang SC. Hyperin inhibits nuclear factor kappa B and activates nuclear factor E2-related factor-2 signaling pathways in cisplatin-induced acute kidney injury in mice. Int Immunopharmacol. 2016 Nov;40:517-23. PMID: 27764742.

20.Zhang J, Fu H, Xu Y, Niu Y, An X. Hyperoside reduces albuminuria in diabetic nephropathy at the early stage through ameliorating renal damage and podocyte injury. J Nat Med. 2016 Oct;70(4):740-8. PMID: 27255369.

21.Jin XN, Yan EZ, Wang HM, Sui HJ, Liu Z, Gao W, Jin Y. Hyperoside exerts anti-inflammatory 
and anti-arthritic effects in LPS-stimulated human fibroblast-like synoviocytes in vitro and in mice with collagen-induced arthritis. Acta Pharmacol Sin. 2016 May;37(5):67486. PMID: 27041460.

22.van Beek JH, de Moor $\mathrm{MH}$, de Geus EJ, Lubke GH, Vink JM, Willemsen $G$, Boomsma DI. The genetic architecture of liver enzyme levels: GGT, ALT and AST. Behav Genet. 2013 Jul;43(4):329-39. PMID: 23580007.

23.Chen $\mathrm{YH}$, Lin FY, Liu PL, Huang YT, Chiu JH, Chang YC, Man KM, Hong CY, Ho YY, Lai MT. Antioxidative and hepatoprotective effects of magnolol on acetaminophen-induced liver damage in rats. Arch Pharm Res. 2009 Feb;32(2):221-8. PMID: 19280152.

24.Liu CM, Zheng YL, Lu J, Zhang ZF, Fan SH, Wu DM, Ma JQ. Quercetin protects rat liver against lead-induced oxidative stress and apoptosis. Environ Toxicol Pharmacol. 2010 Mar;29(2):158-66. PMID: 21787598.

25.Wang JM, Ji LL, Liu H, Wang ZT. Study of the hepatotoxicity induced by Dioscorea bulbifera L. rhizome in mice. Biosci Trends. 2010 Apr;4(2):79-85. PMID: 20448345.

26.Deng R, Hua X, Li J, Chi W, Zhang Z, Lu F, Zhang L, Pflugfelder SC, Li DQ. Oxidative stress markers induced by hyperosmolarity in primary human corneal epithelial cells. PLoS One. 2015 May;10(5):e0126561-76. PMID: 26024535.
27.BehndigA, Svensson B, Marklund SL, Karlsson K. Superoxide dismutase isoenzymes in the human eye. Invest Ophthalmol Vis Sci. 1998 Mar;39:471-5. PMID: 9501855.

28.Yamanaka K, Hasegawa A, Sawamura R, Okada S. Cellular response to oxidative damage in lung induced by the administration of dimethylarsinic acid, a major metabolite of inorganic arsenics, in mice. Toxicol Appl Pharmacol. 1991 Apr;108:205-13. PMID: 2017750.

29.Deponte M. Glutathione catalysis and the reaction mechanisms of glutathionedependent enzymes. Biochim Biophys Acta. 2013 May;1830:3217-66. PMID: 23036594.

30.Dakrory Al, Fahmy SR, Soliman AM, Mohamed AS, Amer SA. Protective and curative effects of the sea cucumber Holothuriaatra extract against DMBAinduced hepatorenal diseases in rats. Biomed Res Int. 2015 Mar;2015:563652-62. PMID: 25821811.

31.Abdel-Moneim AM, Al-Kahtani MA, ElKersh MA, Al-Omair MA. Free RadicalScavenging, Anti-Inflammatory/AntiFibrotic and Hepatoprotective Actions of Taurine and Silymarin against $\mathrm{CCl} 4$ Induced Rat Liver Damage. PLoS One. 2015 Dec;10(12):e0144509-24. PMID: 26659465.

\section{Correspondence:}

Dr. Chengwei Niu

College of Pharmacy, Jiangsu Food and Pharmaceutical Science College

4 Meicheng Road, Huai'an 223001 China niuchengwei10@126.com

Received: Apr 12, 2017

Review: June 13, 2017

Accepted: July 18, 2017
Conflict of interest: none

Financial sources: Science and Technology Plan Project of Huai'an (HAG2015019), and Practice Innovation Training Projects of Jiangsu College students (201513104006Y).

${ }^{1}$ Research performed at College of Pharmacy, Jiangsu Food and Pharmaceutical Science College, and Pathology Department, Huai an Hospital of Huai'an, China. 